JPPKMI 2 (2) (2021)
JURNAL PENELITIAN DAN PENGEMBANGAN
KESEHATAN MASYARAKAT INDONESIA
JPPKMI

\title{
Pengaruh Iklim Kerja Panas Terhadap Kelelahan Kerja pada Operator Steam di PT. XYZ Boyolali
}

\author{
Muhammad Maftuh $^{1} \bowtie$, Titik Haryanti $^{1}$, Syefira Ayudia Johar ${ }^{1}$ \\ ${ }^{1}$ Fakultas Kesehatan Masyarakat, Universitas Veteran Bangun Nusantara Sukoharjo, Indonesia
}

\begin{tabular}{l}
\hline Info Artikel \\
\hline Sejarah Artikel: \\
Diterima Agustus 2021 \\
Disetujui Desember 2021 \\
Dipublikasi Desember 2021 \\
\hline Keywords: \\
Hot Korking Climate, Work \\
Fatigue, Steam Process \\
Employee \\
\hline URL: \\
$\underline{\text { https://iournal.unnes.ac.i }}$ \\
$\underline{\text { d/siu/index.php/ippkmi }}$ \\
$\underline{\text { /article/view/52432 }}$ \\
\hline
\end{tabular}

\begin{abstract}
Abstrak
PT. XYZ perusahaan garmen di Boyolali memiliki sistem sirkulasi udara yang kurang baik dibandingkan perusahaan lain dalam satu kawasan, menyebabkan iklim kerja panas $\left(32^{\circ} \mathrm{C}\right)$. Salah satu sumber panas berasal dari mini boiler pada steam sehingga operator steam merasakan dampak panas paling banyak. Tujuan mengetahui adanya pengaruh iklim kerja panas terhadap kelelahan kerja pada operator steam. Jenis penelitian ini adalah observasi analitik menggunakan metode Cross Sectional. Teknik sampling yang digunakan Purposive Sampling dilaksanakan pada bulan Februari 2020. Untuk mengukur iklim kerja menggunakan Heat Stress Area Monitor sedangkan kelelahan kerja menggunakan Kuesioner Kelelahan Subjektif Industrial Fatigue Research Committee (IFRC) terhadap 36 sampel. Normalitas data menggunakan uji Kolmogorov Smirnov dan analisis data menggunakan uji Regresi Linier Sederhana nilai $\alpha=0,05$. Hasil uji Regresi Linear Sederhana menggunakan SPSS 22 diperoleh nilai sig $=0,000<0,05$ maka hasil dinyatakan signifikan yaitu terdapat pengaruh iklim kerja panas terhadap kelelahan kerja pada operator Steam. Semakin tinggi iklim kerja panas maka semakin besar tingkat kelelahan pekerja.
\end{abstract}

\begin{abstract}
PT. XYZ is Manufacturing Garment Company placed at Boyolali, , this Company has a poor air circulation system because a number of Exhaust Fan installed so limit if compared with other company on the one region, it make temperature at working area so overheat $\left(32^{\circ} \mathrm{C}\right)$. Overheat temperature comes from mini boiler at steam that makes Employee of steam most felt overheated. This research aims to determine correlation hot working climate with working fatigue on steam process employee. Type of research is analytic observation using Cross Sectional method. Sampling technique used is purposive sampling held in february 2020. Research instrument for measuring the working climate is the Heat Stress Area Monitor and to measure work fatigue using the subjective fatigue Industrial Fatigue Research Committee (IFRC) sheet towards 36 samples. Trials data normality using Kolmogorov Smirnov and data anality using Simple Linear regression value $\alpha=0,05$. Simple Linear regression test results using SPSS 22 obtained a value Sig $=0.000<0.05$ then the result is significantly stated that there is a hot working climate influential to work fatigue of steam process employee, where the higher hot working climate, the rate of labor fatigue is increasingly higher.
\end{abstract}

(C) 2021 Universitas Negeri Semarang

Alamat korespondensi:

J1. Letjend Sujono Humardani No.1, Gadingan, Jombor,

Kec. Bendosari, Kabupaten Sukoharjo, Jawa Tengah 57521

E-mail: $\underline{\text { maftuh.mgl@gmail.com }}$ 


\section{PENDAHULUAN}

PT. XYZ merupakan salah satu anak perusahaan garmen terbesar di Indoneisa yang berada di Kabupaten Boyolali, perusahaan ini berada jadi satu dengan lima anak perusahaan yang masih jadi satu grup, dari kelima anak perusahaan ini PT. XYZ memiliki sistem sirkulasi udara yang kurang baik karena memiliki exhaust fan dengan jumlah yang paling sedikit dibandingkan perusahaan lain dengan ukuran gedung yang hampir sama, ditambah lagi perusahaan yang lain sudah menerapkan space cooling yaitu udara dingin yang dialirkan ke seluruh ruangan dalam rangka untuk mengurangi suhu secara keseluruhan atau mendinginkan area kerja dan di PT. XYZ belum menerapkannya. Selain sinar matahari sebagai sumber panas area kerja juga terdapatu sumber panas yang berasal dari mini boiler sebagai penghasil panas yang dialirkan menuju ke steam dimana operator steam yang paling dekat dengan mini boiler yang merasakan dampak panas paling banyak. Berdasarkan survei pendahuluan yang dilakukan di PT. XYZ peneliti telah mendapatkan data hasil pengukuran pada bulan September 2019 menggunakan alat Environment meter krisbow 4 in 1 pada pukul 08:00 didapatkan suhu $26^{\circ} \mathrm{C}$, sedangkan suhu paling tinggi didapatkan pada pukul 14:00 dengan suhu $36^{\circ} \mathrm{C}$. Pengukuran kelelahan kerja menggunakan lembar kuesioner kelelahan subjektif yaitu Industial Fatigue Research Committee (IFRC) terhadap 10 karyawan di tempat kerja didapatkan hasil pada pagi hari $50 \%$ karyawan mengalami kelelahan ringan dan 50\% karyawan mengalami kelelahan sedang, untuk pengukuran siang hari mengalami peningkatan kelelahan kerja dengan didapatkan $70 \%$ karyawan mengalami kelelahan sedangan $30 \%$ mengalami kelelahan tinggi.

Operator steam ialah tenaga kerja departemen sewing yang mempunyai proses untuk merapikan pakaian dengan menyeterika menggunakan jenis setrika dimana pemanasnya berasal dari mesin mini boiler. Boiler atau ketel uap adalah suatu alat berbentuk bejana tertutup yang digunakan untuk menghasilkan steam.
Steam diperoleh dengan memanaskan bejana yang berisi air dengan bahan bakar (Yohana,2009).

Di dalam lingkungan kerja, pekerja akan menghadapi beban tambahan akibat lingkungan kerja. Beban tambahan akibat lingkungan kerja tersebut dapat berasal dari faktor kimiawi, fisik, biologis, fisiologis, pisikis. Temperatur yang terlalu panas menjadikan perasaan cepat lelah dan mengantuk, sebaliknya temperatur yang terlalu dingin dapat mengurangi daya atensi dan ketidaktenangan yang berpengaruh negatif terutama pada kerja mental, namun lingkungan kerja dengan suhu tinggi lebih banyak menimbulkan permasalahan dibandingkan dengan lingkungan kerja dengan suhu rendah karena manusia lebih mudah melindungi diri dari pengaruh suhu rendah dibandingkan dengan suhu tinggi, sedangkan suhu nyaman bagi orang Indonesia adalah antara $24-26^{\circ} \mathrm{C}$ (Suma'mur, 2014).

Indeks Suhu Basah dan Bola (Wet Bulb Globe Temperature Index) yang selanjutnya yang selanjutnya disingkat ISBB adalah parameter untuk menilai tingkat iklim kerja panas yang merupakan hasil perhitungan anatara suhu udara kering, suhu basah alami dan suhu bola.Suhu kering adalah suhu yang ditunjukan oleh thermometer bola basah alami (Natural Wet Bulb Thermometer), Suhu Basah Alami adalah suhu yang ditunjukan oleh thermometer bola basah alami Suhu Bola adalah suhu yang ditunjukan oleh thermometer bola (Permenaker No.5 Tahun 2018).

Salah satu dari penyebab kelelahan adalah lingkungan kerja yang ekstrim. Kelelahan adalah suatu mekanisme perlindungan tubuh agar tubuh terhindar dari kerusakan lebih lanjut sehingga terjadi pemulihan setelah istirahat. Kelelahan diatur secara sentral oleh otak. Pada susunan syaraf pusat terdapat sistem aktifitas bersifat simpatis dan inhibisi bersifat parasimpatis. Istilah kelelahan biasanya menunjukkan kondisi yang berbeda-beda dari setiap individu, tetapi semuanya bermuara kepada kehilangan efisiensi dan penurunan kapasitas kerja serta ketahanan tubuh (Tarwaka, 2014). 
Subjective Self Rating Test dari Industrial Fatigue Research Committee (IFRC) Jepang, merupakan salah satu kuesioner yang dapat untuk mengukur tingkat kelelahan subyektif. Tarwaka, dkk (2014) menjelaskan bebrapa metode yang dapat digunakan dalam pengukuran subyektif. Metode antara lain : ranking methods, rating methods, quesionaire methods, interview dan checklist.

Keaslian penelitian ini berdasarkan pada beberapa penelitian terdahulu yang mempunyai karakteristik yang relatif sama pada Susanto (2015) tentang "Pengaruh Iklim Kerja Panas Terhadap Kelelahan Pada Pekerja Di Bagian Sizing Pt. Iskandar Indah Printing Textile Surakarta". Kesamaan penelitian ini pada tujuan penelitian untuk mengetahui pengaruh iklim kerja panas terhadap kelelahan kerja,metode survei analitik dengan pendekatan cross sectional. Sedangkan perbedaanya anatara peneliti dengan Susanto (2015) terdapat pada alat pengukuran yang digunakan untuk mengukur kelelahan kerja menggunakan reaction timer L77 Lakassidaya. Analisa data menggunakan uji Chi Square sehingga tidak bisa menampilkan seberapa besar pengaruh iklim kerja panas terhadap kelelahan kerja.

\section{METODE}

Penelitian ini menggunakan jenis penelitian observational analitik dengan menggunakan pendekatan cross sectional. Variabel bebas adalah variabel yang menjadi sebab timbulnya atau berubahnya variabel terikat, variabel bebas dalam penelitian ini adalah iklim kerja panas, Variabel terikat adalah variabel yang dipengaruhi atau menjadi akibat karena adanya variabel bebas, variabel terikat dalam penelitian ini adalah kelelahan kerja. Variabel pengganggu adalah variabel yang mempengaruhi antara variabel bebas dan variabel terikat, variabel pengganggu dalam penelitian ini yaitu area kerja dengan tingkat iklim kerja yang berbeda-beda, dikendalikan dengan cara mengkategorikan iklim kerja berdasarkan nilai ambang batas (NAB). Penelitian ini dilaksanakan di PT. XYZ
Boyolali, Mojosongo Boyolali Jawa Tengah pada bulan Februari 2020.

Pengambilan sampel dilakukan secara purposive sampling merupakan suatu teknik untuk menentukan sampel penelitian dengan beberapa pertimbangan tertentu yang bertujuan agar data yang diperoleh nantinya bisa lebih representatif (Sugiyono, 2012). Kriteria Inklusi yakni karakteristik sampel yang dapat dimasukkan untuk layak diteliti. Adapun kriteria sampel yang akan diteliti adalah : (1) Usia 20-40 tahun, (2) Jenis kelamin Laki-laki, (3) Masa kerja minimal 1 tahun, (4) Status Gizi dengan Indek Masa Tubuh (IMT) normal, (5) Kondisi kesehatan fit, (6) Beban kerja ringan, (7) Variasi kerja operator steam, (8) Shift kerja pagi, (9) Sedangkan kriteria eksklusi pada sampel ini adalah Responden tidak dapat izin dari atasan saat pengambilan danResponden sedang banyak pekerjaan ketika pengambilan data. Berdasarkan jumlah keseluruhan operator steam sebanyak 60 orang yang memenuhi kriteria inklusi 36 karyawan.

Data merupakan faktor yang paling penting dalam penelitian, karena tujuan utama dalam penelitian adalah mendapatkan data tanpa mengetahui teknik pengumpulan data, maka peneliti tidak akan mendapatkan data yang memenuhi standar data yang ditetapkan, untuk itu diperlukan teknik tertentu dalam pengumpulan data. Teknik pengumpulan data dapat dilakukan dengan; (1) Pengukuran menggunakan alat ukur Area Heat Stress Monitor untuk mengukur iklim kerja panas di departemen sewing khususnya untuk karyawan operator steam hasil dari pengukuran iklim kerja ini dalam satuan ${ }^{\circ} \mathrm{C}$ dan membagikan lembar Kuesioner Kelelahan Subjektif Industial Fatigue Research Committee (IFRC) kepada karyawan untuk mengukur kelelahan subjektif dalam satuan skor. (2) Wawancara adalah percakapan yang dilakukan oleh dua pihak yaitu pewawancara (interviewer) yang mengajukan pertanyaan dan terwawancara yang memberikan jawaban atas pertanyaan. Tujuan dari wawancara ini adalah untuk menemukan permasalahan secara terbuka, dimana pihak yang diajak wawancara diminta pendapat, dan 
ide-idenya. Wawancara dilakukan untuk memastikan responden yaitu karyawan operator steam sesuai dengan kriteria inklusi. (3) Metode dokumentasi adalah metode pengumpulan data yang datanya diperoleh dari buku, internet, atau dokumen lain yang menunjang penelitian yang dilakukan. Dokumen merupakan catatan mengenai peristiwa yang sudah berlalu. Peneliti mengumpulkan dokumen yang dapat berupa tulisan, gambar, atau karya-karya monumental dari seseorang (Sugiyono. 2012). Dokumen bisa berbentuk tulisan, gambar proses pengambilan data, hasil pengukuran, dan peraturan-peraturan prndukung dalam penelitian.

Sumber data dalam penelitian ini menggunakan data primer dan data sekunder. Data primer adalah data yang diperoleh langsung melalui sampel penelitian dengan teknik pengukuran menggunakan alat Area Heat Stress Monitor. Data primer juga diperoleh langsung dari responden melalui kuesioner. Sebelum mengisi kuesioner responden diberi penjelasan tentang cara mengisi kuesioner. Setelah kuesioner diterima oleh responden, responden langsung mengisi kuesioner yang diberikan sesuai dengan ketentuan yang ada. Data sekunder adalah pengumpulan data yang diperoleh dari orang atau tempat lain dan bukan dilakukan oleh peneliti sendiri berupa data hasil pengukuran iklim kerja yang dilakukan oleh perusahaan, data personal tenaga kerja pabrik, literature $\mathrm{k} 3$, jurnal $\mathrm{k} 3$, buku-buku pedoman, referensi berkaitan dengan penelitian yang akan di laksanakan.

Analisis univariat dilakukan untuk mengetahui gambaran masing-masing variabel yang diteliti baik variabel bebas maupun variabel terikat (Sugiyono, 2012). Variabel bebas pada penelitian ini adalah iklim kerja panas dan variabel terikatnya adalah kelelahan kerja. Data variabel dimasukan dalam bentuk beberapa kategori kemudian distribusikan dalam frekuesni untuk selanjutnya dianalisa. Analisa bivariat bertujuan untuk melihat pengaruh terhadap dua variabel yatu variabel terikat dan variabel bebas yang diduga berhubungan atau kolerasi (Notoatmojo, 2012). Dalam penelitian uji bivariat ini digunakan untuk megetahui pengaruh iklim kerja panas terhadap kelelahan kerja pada operator steam PT. XYZ Boyolali. Menggunakan uji Regresi Linear Sederhana dengan tingkat signifkan $\alpha \leq 0,05$ dengan tingkat kepercayaan 95\%. Pengolahan data menggunakan bantuan program komputer dengan interpretasi hasil. Jika $\mathrm{p}$ value $\leq 0,05$ maka Ho diterima dan jika $p$ value $>0,05$ maka Ho ditolak (Wibowo, 2012).

\section{HASIL DAN PEMBAHASAN}

Pengukuran iklim kerja pada 6 (empat) titik pengukuran pada jam 13.00 - 15.00 WIB. Pengukuran yang dilakukan dengan menggunakan Area Heat Stress Monitor didapatkan hasil pada tabel 1.

Pengukuran iklim kerja menggunakan alat Area Heat Stress Monitor dilakukan di 6 (enam) titik, sebelumnya kita harus menetapkan Nilai Ambang Batas (NAB), terlebih dahulu kita harus mengetahui beban kerja pekerja di tempat tersebut. Kategori beban kerja pekerja bisa diketahui dari banyaknya denyut nadi

Tabel 1. Distribusi Hasil Pengukuran Iklim Kerja Berdasarkan Titik Pengukuran

\begin{tabular}{|c|c|c|c|c|c|c|c|}
\hline Titik & $\begin{array}{l}\text { Suhu Basah } \\
\text { Alami }\left({ }^{\circ} \mathrm{C}\right)\end{array}$ & $\begin{array}{l}\text { Suhu } \\
\left({ }^{\circ} \mathrm{C}\right)\end{array}$ & kering & $\begin{array}{l}\text { Suhu Bola } \\
\left({ }^{\circ} \mathrm{C}\right)\end{array}$ & $\begin{array}{l}\text { ISBB } \\
\left({ }^{\circ} \mathrm{C}\right)\end{array}$ & Kategori & $\begin{array}{l}\text { Rata-rata } \\
\left({ }^{\circ} \mathrm{C}\right)\end{array}$ \\
\hline \multicolumn{8}{|c|}{ Area Dekat Pintu } \\
\hline Line $1-5$ & 28 & 32,2 & & 34,6 & 29,98 & $<\mathrm{NAB}$ & \\
\hline Line 6-10 & 28,3 & 33,1 & & 35,2 & 30,37 & $<\mathrm{NAB}$ & \\
\hline Line $26-30$ & 28,2 & 32,7 & & 34,9 & 30,21 & $<\mathrm{NAB}$ & 30,2 \\
\hline \multicolumn{8}{|c|}{ Area Jauh Pintu } \\
\hline Line $11-15$ & 30,4 & 34 & & 35,5 & 31,93 & $>\mathrm{NAB}$ & \\
\hline Line PPA & 29,7 & 33,5 & & 35 & 31,29 & $>\mathrm{NAB}$ & 32 \\
\hline $\begin{array}{l}\text { Line } \\
\text { Artwork }\end{array}$ & 31,2 & 35,3 & & 36,3 & 32,73 & $>\mathrm{NAB}$ & \\
\hline
\end{tabular}


Tabe1 2. Distribusi Responden Berdasarkan Kelelahan Kerja

\begin{tabular}{|c|c|c|c|c|}
\hline No. & Kategori & Frekuensi & Persentase & Nilai Rata-Rata IFRC \\
\hline \multicolumn{5}{|c|}{ Area Dekat Pintu } \\
\hline 1. & Kelelahan Ringan & 11 & $31 \%$ & \multirow[b]{2}{*}{20,4} \\
\hline 2. & Kelelahan Sedang & 7 & \multirow{2}{*}{$23 \%$} & \\
\hline \multicolumn{4}{|c|}{ Area Jauh Pintu } & \\
\hline 3 & Kelelahan Ringan & 3 & $8 \%$ & \multirow{3}{*}{31,7} \\
\hline 4 & Kelelahan Sedang & 15 & $42 \%$ & \\
\hline & Jumlah & 36 & $100 \%$ & \\
\hline
\end{tabular}

perkerja per menit. Dari hasil penelitian, dapat diketahui bahwa rata-rata denyut nadi pekerja sebanyak $88 \mathrm{kali} / \mathrm{menit}$, denyut nadi tersebut maka termasuk kategori beban kerja ringan. Selanjutnya kategori beban kerja tersebut dibandingkan dengan dengan standar Permenaker Nomor 5 Tahun 2018 tentang K3 Lingkungan Kerja dengan standar paparan panas yang dapat diterima oleh tenaga kerja dengan lama kerja $100 \%$ dengan beban kerja ringan berdasarkan denyut nadi adalah sebesar $31{ }^{\circ} \mathrm{C}$ dengan lama paparan 8 jam per hari.

Pengukuran yang dilakukan di area dekat dengan pintu didapatkan nilai ISBB rata-rata $30,2{ }^{\circ} \mathrm{C}$, nilai ini masih dibawah $\mathrm{NAB}$, sedangkan untuk area jauh dengan pintu dengan nilai ISBB rata-rata $32^{\circ} \mathrm{C}$ melebihi nilai ambang batas. Perbedaan nilai ISBB antara dua area disebabkan karea area yang berada di dekat pintu operator steam mendapatkan suplai udara segar yang banyak, sedangkan untuk yang jauh dari pintu suplai udara segar yang masuk sedikit ditambah lagi dengan area kerja yang panas. Sumber panas area kerja bersumber dari mesin boiler mini dimana panasnya dialirkan ke alat steam yang digunakan untuk merapikan garmen, disamping itu sumber panas juga dihasilkan dari mesin press. Gedung perusahaan menggunakan atap mika transparan dimana material tersebut mudah menghantarkan panas dari sinar matahari diluar gedung serta sebagai pencahaayan area kerja secara alami menggunakan bantuan sinar matahari untuk mendukung pencahayaan dari lampu jumlahnya banyak hal ini menyebabkan suhu area kerja semakin panas, maka sesuai dengan pengukuran iklim kerja dimana area yang jauh dari pintu iklim kerja semakin panas karea aliran sirkulasi udara segar tidak sebagus di area yang dekat dengan pintu.

Hasil pengukuran kelelahan pada tenaga kerja dengan menggunakan kuesioner IFRC dengan 8 jam kerja dan 1 jam istirahat dapat dilihat pada tabel 2 .

Berdasarkan tabel 2 di atas, menunjukkan bahwa responden pada operator steam area jauh pintu yang mengalami kelelahan kerja ringan yaitu sebanyak 3 orang (8\%), kelelahan sedang sebanyak 15 orang (42\%). Nilai rata-rata pengukuran IFRC 31,7 termasuk dalam kategori kelelahan sedang. Distribusi frekuensi dari jawaban secara keseluruhan menunjukan bahwa skor terbanyak dari setiap pertanyaan secara berurutan skor tinggi ke rendah 6 teratas meliputi merasa haus, merasa berat dikaki, lelah pada seluruh badan, merasakan nyeri di bagian punggung, sering menguap pada saat bekerja, dan merasa mengantuk.

Dalam ji Parametrik sebelum melakukaan uji hubungan kedua variabel maka dilalukan uji Kolmogorov Smirnov bertujuan untuk mengetahui apakah nilai terdistribusi normal atau tidak, jika sig $>0,5$ maka nilai terdistribusi normal, berdasarkan hasil uji normalitas diketahui nilai Sig 0,2 >0,05, maka dapat disimpulkan nilai terdistribusi normal. Berikut hasil perhitungan regresi linier sederhana.

Berdasarkan uji regresi linier sederhana terhadap 36 responden diperoleh hasil signifikan (Sig) antara iklim kerja panas dengan kelelahan kerja operator steam dengan nilai Sig 0,000 $<0,05$ nilai tersebut menunjukan bahwa sig lebih kecil dari 0,05 maka Ho diterima yang berarti ada pengaruh yang signifikan antara iklim kerja 
Tabel 3. Hasil Penghitungan Regresi Linier Sederhana Iklim Kerja Panas dengan Kelelahan Kerja

\begin{tabular}{lllll}
\hline \multicolumn{2}{l}{ Model Summary } & & & \\
\hline Model & $R$ & $R$ Square & Adjusted $R$ Square & Std. Error of the Estimate \\
\hline 1 &, $733^{\mathrm{a}}$ &, 537 &, 523 & 6,351 \\
\hline Coefficients $^{n}$ & & & &
\end{tabular}

\begin{tabular}{|c|c|c|c|c|c|c|}
\hline & \multirow[b]{2}{*}{ Model } & Unstandardize & \multicolumn{3}{|c|}{ Standardized } & \\
\hline & & B & Std. Error & $\frac{\text { Coefficients }}{\text { Beta }}$ & $t$ & $\mathrm{Sig}$ \\
\hline 1 & (Constant) & $-189,792$ & 34,395 & & $-5,518$ & ,000 \\
\hline & Iklim Kerja Panas & 6,958 & 1,108 & ,733 & 6,279 &, 000 \\
\hline
\end{tabular}

panas dengan kelelahan kerja operator steam, sementara untuk besarnya nilai hubungan $(\mathrm{R})$ terdapat pada tabel Model Summary sebesar 0,733 dari output tersebut diperoleh koefisien determinasi ( $R$ Square) 0,537 artinya besarnya pengaruh iklim kerja panas terhadap kelelahan kerja pada operator steam adalah sebesar 53,7\%.

Hasil Pengukuran iklim kerja menunjukan bahwa area jauh dari pintu memiliki ISBB lebih tinggi yaitu sebesar $32^{\circ} \mathrm{C}$ (>NAB) serta untuk kelelahan kerja memiliki nilai rata-rata IFRC sebesar 31,7 (kelelahan kerja sedang) sedangkan untuk area yang dekat dengan pintu hasilnya berbanding terbalik yaitu memiliki hasil ISBB sebesar $30,2^{\circ} \mathrm{C}(<\mathrm{NAB})$ dengan nilai rata-rata IFRC kelelahan kerja sebesar 20,4 (kelelahan kerja ringan), hal ini menunjukan bahwa area yang berada di atas NAB memiliki nilai kelelahan yang lebih tinggi dari area yang dibawah $\mathrm{NAB}$, artinya semakin tinggi iklim kerja panas maka tingkat kelelahan pekerja semakin tinggi dan sebaliknya semakin rendah iklim kerja panas maka tingkat kelelahan akan semakin rendah.

Berdasarkan hasil uji regresi linier sederhana diperoleh hasil signifikan (Sig) yaitu 0,000 dimana nilai $\mathrm{Sig}<0,05$. Nilai tersebut menunjukan bahwa ada pengaruh yang signifikan antara iklim kerja panas terhadap kelelahan kerja operator steam pada PT XYZ di Boyolali.

Besarnya nilai pengaruh (R) terdapat pada tabel Model Summary yaitu sebesar 0,733 dari output tersebut diperoleh koefisien determinasi ( $\mathrm{R}$ Square) 0,537 yang berarti bahwa besarnya pengaruh iklim kerja panas terhadap kelelahan kerja adalah sebesar 53,7\%. Hasil ini menunjukan bahwa iklim kerja panas memiliki pengaruh yang besar terhadap kelelahan kerja yang dialami operator steam di PT XYZ di Boyolali. Dari proses steam yang menyebabkan paparan panas terhadap opeator steam ditambah dengan iklim kerja yang panas yang terus menerus terpapar suhu panas ini berdasarkan kuesioner IFRC menyebabkan operator steam merasa haus dan merasakan nyeri di bagian punggung yang termasuk dalam kategori kelelahan fisik, diikuti dengan melemahnya kegiatan dengan gejala merasa berat dikaki, lelah pada seluruh badan, sering menguap pada saat bekerja, dan merasa mengantuk. Hasil ini sejalan dengan pendapat (Suma'mur, 2014) bahwa temperatur yang terlalu panas menjadikan perasaan cepat lelah dan mengantuk. Dengan demikian penyimpangan dari batas kenyamanan iklim kerja akan berdampak buruk pada kelelahan kerja. Pihak perusahaan perlu melakukan tindakan perbaikan iklim kerja yang nyaman untuk menghindari dari kerugikan yang disebabkan karena pekerja yang mengalami kelelahan karena panas yang menyebakan penurunan produktivitas kerja dan pada akhirnya akan menyebabkan perusahaan mengalami kerugian.

Hasil tersebut juga sejalan dengan penelitian yang dilakukan oleh Susanto (2015) tentang "Pengaruh Iklim Kerja Panas Terhadap Kelelahan Pada Pekerja Di Bagian Sizing Pt. Iskandar Indah Printing Textile Surakarta" berdasarkan hasil penghitungan Chi Square menunjukan nilai 6.652 dengan p-value 
$0,025<0,05$ yag artinya H0 ditolak, atau ada pengaruh yang signifikan antara iklim kerja terhadap tingkat kelelahan kerja. Dimana semakin iklim kerja panas > NAB memberikan kecenderungan tingkat kelelahan kerja yang semakin tinggi.

\section{PENUTUP}

Hasil pengukuran iklim kerja pada area dekat dengan pintu dengan nilai rata-rata $30,2^{\circ} \mathrm{C}$ masih dibawah nilai ambang batas $(<\mathrm{NAB})$ dan area jauh dengan pintu dengan nilai rata-rata $32^{\circ} \mathrm{C}$ melebihi nilai ambang batas (>NAB) sedangkan hasil pengukuran kelelahan kerja area yang jauh dari pintu memiliki skor IFRC rata-rata 31,7 termasuk dalam kategori kelelahan sedang dan area dekat dengan pintu sebesar 20,4 termasuk dalam kategori kelelahan ringan. Gejala kelelahan yang dialami oleh operator steam paling berpengaruh ialah kelelahan fisik. Berdasarkan hasil uji regresi linier sederhana diperoleh hasil signifikan (Sig) yaitu 0,000 dimana nilai $\mathrm{Sig}<0,05$ menunjukan bahwa ada pengaruh yang signifikan iklim kerja panas terhadap kelelahan kerja operator steam di PT XYZ Boyolali.

Peneliti lain dapat melalukan penelitian lebih lanjut dengan referensi penelitian yang telah dilakukan, bisa dengan sampel yang lebih banyak, atau dengan penambahan variabel yang berbeda tentang gangguan kesehatan lain yang berhubungan dengan iklim kerja panas.

\section{DAFTAR PUSTAKA}

Peraturan Mentri Ketenagakerjaan Republik Indonesia Nomor 5 Tahun 2018 tentang Keselamatan dan Kesehatan Kerja Lingkungan Kerja.

Sugiyono. 2012. Metode Penelitian Kuantitatif Kualitatif dan $R \& D$. Bandung : Alfabeta.

Suma'mur. 2014. Higiene Perusahaan dan Kesehatan Kerja (HIPERKES). Jakarta : Sagung Seto.

Susanto, Agus. 2015. Pengaruh Iklim Kerja PAnas Terhadap Kelelahan pada Pekerja di Bagian Sizing PT. Iskandar Indah Printing Textile Surakarta. Skripsi. Surakrata : Fakultas Ilmu Kesehatan Universitas Muhammadiyah Surakarta.

Tarwaka. 2014. Keselamatan dan Kesehatan Kerja. Manajemen dan Implementasi K3 di Tempat Kerja. Surakarta: Harapan Press, Hal: 1.

Yohana, E. dan Askhabulyamin. 2009. Perhitungan Efisiensi Dan Konversi Dari Bahan Bakar Solar Ke Gas Pada Boiler Ebara HKL 1800 KA. Jurnal Teknik Mesin. 11 (3): 13-16.

Wibowo, AE. 2012. Aplikasi Praktis SPSS Dalam Penelitian. Yogyakarta : Gava Media. 